\title{
Ramayana Trail as a Cultural Tourism Product in Sri Lanka: New Paradigm for Destination Marketing
}

\author{
Fernando P.I.N. ${ }^{1}$, Pabasara Sarangi \\ Faculty of Management, Uva Wellassa University, Badulla \\ imalif@uwu.ac.lk, sarangi.pabasara@yahoo.com
}

\begin{abstract}
Tourism could consider as the most booming sector in service economy where the novel paradigms popular among tourism destination that leads for huge competition. Ramayana Trail is an untapped market, which symbolizes eminent synthesis of Sri Lankan and Indian cultural values. Ramayana Trail is featured novelty nature in tourism industry which was recognized by the least and crucial to promote as more than fifty sites were located in Sri Lanka with the ability to influence tourists for diversified experiences. The objective of the study to identify the potentiality to promote of Ramayana Trail as a cultural tourism product with special reference to Uva and central province through the investigation of tourist's profile, existing awareness and destination attributes. Sample size is 120 tourists and for data collection semi structured questionnaire and interview method were adopted. Findings reveal that the existing level of awareness is low among foreign tourists. Comparably Indian tourists are aware about the legend but not for the Ramayana sites. Attraction has been identified as the most significance destination attributes and promotion of Ramayana trail as a cultural tourism product has been recommended through government intervention and websites, blogs and social media marketing tools.
\end{abstract}

Keywords: Cultural tourism, promotion, Ramayana Trail, Sri Lanka

\section{Introduction}

Ramayana is one of greatest historical epics erected about Sri Lankan and Indian history. This represents both Sri Lankan and Indian cultural values, religious values, rituals and symbols as this legend has mainly built around magnanimous historical characters in History, the great king Rawana, god Rama and Seetha Devi. Ramayana trail was deeply believed by most of Indians and plays major role in Indian religion. Majority of Ramayana sites were located around Sri Lanka where rich by fabulous natural beauty. This trail represent

(iD) http://orcid.org/0000-0001-9487-5569 
some feature of cultural tourism as it is a subdivision of main tourism related to the culture of an area or a country in specific geographical areas, particularly the lifestyle, along with the art of those people, their religion, history and other factors of their lifestyle (Foad et al. 2014). The World Tourism Organization (WTO) predicts that cultural tourism will be one of the five key tourism market segments in the future, and the growth in this area will present an increasing challenge in terms of managing visitor flows to cultural sites. World Tourism Organization defines cultural tourism as movements of persons essentially for cultural motivation such as study tours, performing arts and cultural tours, travel to festivals and other events, visit to sites and monuments, travel to study nature, folklore or art and pilgrimages. According to this definition, Ramayana trail can be considered as part of cultural tourism element due to historical characters, historical events, cultural sites, monuments and related attractions. Cultural and Heritage tourism marked tremendous growth during international arena and this market will be successful by increasing the number of domestic or international tourists (Foad et al. 2014). Although, Ramayana trail represents cultural values this is not promoted among international tourists where the Sri Lankan tourism in a paradigm to increase the tourism income rather the number of visitors (Fernando, 2015). Therefore this research study has examined significant factors which assist to promote Ramayana trail by evaluating destination attributes and tourist awareness and deeply examined the impact of destination attributes to promote Ramayana Trail. There are more than 50 sites related to Ramayana, the great Indian epic read and loved by the many Asians and the sites related to important events in the epic Ramayana from the place of Seetha Devi's captivity to the place where Rama lord slew Rawana, the king of Lankapura. People living in the areas where these events took place, still remember the connection of their village to the great history of Ramayana. Village court at the area where Seetha Devi undertook "Agni Pariksha" is still considered valid if oaths taken at that place. The soil of the battlefields of Ramayana is still remains in red color surrounded by lighter colored soil and exotic Himalayan herbs are found suddenly among the tropical Sri Lankan forests \& mountains (Ramayana Tours,2016). Ramayana trail would be assist to upgrade cultural tourism in Sri Lanka since this is an untapped and niche segment in cultural tourism. Moreover Ramayana sites are depleted with natural attraction and combined with special incident in Ramayana Trail. Therefore the legend can be promoted hence unique cultural and historical feature of Ramayana Trail. 
Cultural heritage tourism has long existed, but recent demographic, social, and cultural changes in the main source countries have led to an increasing number of new niche markets in destination countries, including culture-oriented holidays. Cultural heritage tourism is important for various reasons; positive economic and social impact, establishes and reinforces identity, preserve the cultural heritage, with culture as an instrument, facilitates harmony and understanding among people, supports culture and helps renew tourism (Norhasimah et al.2015). Niche markets could be directly focus on specific visitors willing to visit Ramayana sites as Ramayana trail has belonged to pre historical period, this has replete with cultural and historical values which can be posed for the visitors.

\section{Research Problem}

The study focused to identify existing level of awareness and destination attributes and key barriers and opportunities to promote Ramayana Trail. As a comparison, statistics of tourist arrival according to the purpose of visit there are $0.01 \%$ tourists with the purpose of religious and culture (SLTDA, 2014). And it exhibit there are less number of tourist's arrival to Sri Lanka to visit cultural destinations although a cultural tourism is a booming sector in World wide. Since the tourism focuses to identify novel avenues to promote the sector, Ramayanaya Trail could be promoted as a cultural tourism product. Therefore this research will examine potentials to promote Ramayana trail to general market as a tourism attraction in Sri Lanka and also will identify opportunities and barriers to promote Ramayana trail as a cultural tourism product. Hence the Research questions of this study thereby are derived from the explained problem to identify promotion of Ramayana Trail as a cultural tourism product while considered current scenario.

Research Questions:

- Which is the most influencing destination attribute on promoting Ramayana Trail in Uva and Central provinces, Sri Lanka?

- What is the existing level of awareness of international tourists about Ramayana Trail?

- What are the key barriers and opportunities to promote Ramayana Trail as a cultural tourism product?

Research Objectives has been developed;

- To identify most influencing destination attributes on promoting Ramayana Trail in Uva and Central province, Sri Lanka

- To identify existing level of awareness of international tourists about Ramayana Trail 
- To identify key barriers and opportunities to promote Ramayana Trail as a cultural tourism product

\section{Review of Literature}

Legend is a part of culture and history of specific region. Ramayana, one of the two great epics of India is idealistic in the handling of human characters and scholars view the legend as a storehouse of ancient knowledge, Philosophy, religion, customs and rituals, polity, science, social life, geography, history, economics, code of conduct (Balambal, 2013). According to the legend, Rawana is a tragic hero not a villain as Lankan populace valued cultural values greater than power or strength. Rama accepted Rawana as a Brahmin scholar in Sanskrit and a great king and ordered a cremation suitable for a great king and Brahmin. Rawana is a chief character in Ramayana and is of immense moral and physical strength and there existed inscriptions and locations pertaining to Rawana, Rama, and Seetha in Sri Lanka (Jayasinghe, 2013). According to this Ramayana represents great cultural, historical and religious features and also this legend has framed around great three historical characters. According to (Hofstede, 1997) Culture refers to the "cumulative deposit of knowledge, experience, beliefs, values, attitudes, meanings, hierarchies, religion, notions of time, roles, spatial relations, concepts of the universe, and material objects and possessions acquired by a group of people in the course of generations through individual and group striving". Further there are antagonistic believes in the society, as Indian culture identified king Rawana as an enemy while Sri Lankan as one of great kings in the history.

Cultural tourism is defined as "visits by persons form outside the host community motivated wholly or in part by interest in the historical artistic, scientific or lifestyle/heritage offerings of a community, region, group or institution' (Silberberg, 2006). Within a modern tourism format the culture element, which is inherent or representative of tourism destinations, plays a vital role in attracting tourists or enhancing the value of heritage constructions. Cultural tourism began to be recognized as a distinct product category in late 1970's when tourism marketers and researchers realized that some people traveled specifically to gain a deeper understanding and knowledge of the culture or heritage of a destination. People are willing to exposure different cultural value by travelling to various cultural destinations (Tighe, 1986). Cultural tourism is considered as a sub segment of tourism related to the culture of a specific geographical area; lifestyle, religion, history and other factors. Cultural tourism consist tourism in major and large and historical cities and urban areas, and their cultural 
elements. It also contains the tourism in rural zones to show the rituals and civilizations of local cultural communities and way of their life and values (Prentice, 2001). Further cultural tourism is categorized among one of the five types of tourism and form of special interest tourism, where culture forms the basis of either attracting tourists or motivation people to travel (Mckercher \& du cros, 2002). Cultural tourism also includes the experiential element by which means tourists want to get educated by experiencing culture in their journey. As a minimum, cultural tourism involves experiencing or having contact of differing intensity with the unique social fabric, heritage, and special character of places (Mckercher \& du cros, 2002). Cultural heritage tourism viewed as travel anxious with experiencing cultural environments, including landscapes, the visual and performing arts, and special lifestyles, values, traditions and events. It is vital to stress that cultural heritage tourism involves not only tangible or visible heritage such as sites, colors, materials, and settlement patterns, but also intangible heritage such as societal structures, traditions, values, and religion (Norhasimah et al.2015). A cultural resource can be defined as any cultural feature, tangible (material) or intangible (non-material), available within a country, region or area, which makes a positive contribution to cultural tourism (Ivanovic, 2008). Cultural tourism resource is created by human being rather than a nature born. It involves the process of the development of history, science, life style, arts and other human creative achievement (Zhang, 2011) and represents features such as historical, arts, manmade creations. Cultural tourism encompass the unique features of a place which reflect its culture, history, or environment, and by their experiential nature, promote the rich tapestry of cultural traditions, ethnic backgrounds and landscapes (Copley \& Robson, 1996). A cultural attest is not a cultural tourism product unless it transforms itself into products that could be consumed by tourists. But cultural tourism product must involve the cultural values through the transformation process. Ramayana Trail could be generating above both compositions because this trail has built with local cultural value, some monuments such as Seetha kotuwa, some people are worshiping king Rawana as a god. As Ramayana has a prehistorically values this would be educated people regarding pre historical period and this would be created imagination in tourist mind when they have aware about flow of the story such as king Rawana's vehicle dadhu Monara. This has created curiosity in people's mind and this is questionable Sri Lankan prehistory has a technological advancement to fly over air. This legend could be promoted by indicating eminent cultural values to tourists as legend has attractable features such as great story board, indicate human relationships, and indicate Indian and Sri Lankan rituals. By indicating these values this trail could be promoted to 
tourists with the specialty of Ramayana sites. Each Ramayana site has combined with special incident of Ramayana trail and the sites within Sri Lanka; Seetha Kotuwa, Diwurumpola,Seetha Amman temple, Seetha Eliya, Laggala, Rawana waterfall, Rawana cave (Ramayana Tours, 2016). Destinations can be defined as places which offer an amalgam of tourism products and services, which are consumed under a brand name of the destination. Scholars viewed it as geographical regions, understood by visitors as unique entities with a core of six main provisions; Attractions, accessibility, available packages activities and ancillary services (Buhalis, 2009). Through the product related approach is considering about destination capabilities which are mentioned as (Hudson \& Ritchie, 2006) the destination should contain with particular facilities to do tourism activities. Hence the study focus on promoting the Ramayana Trail by addressing destination attributes in current tourism destination practices to uplift socio-economic development of the residents in the tourism destination as a whole.

\section{Conceptual Framework}

Independent variables Dependent variable

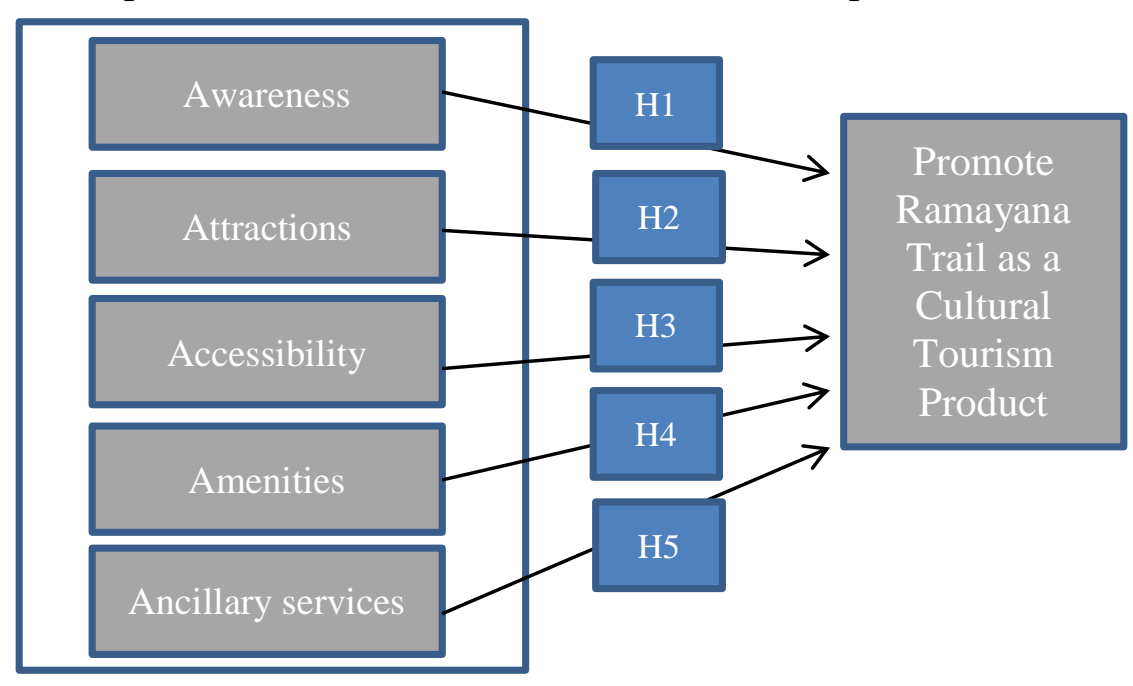

Fig. 01: Conceptual framework developed based on literature

\section{Hypothesis Development}

$\mathrm{H} 1$ : There is a positive relationship between awareness and promoting Ramayana Trail

$\mathrm{H} 2$ : There is a positive relationship between attraction and promoting Ramayana Trail

H3 : There is a positive relationship between accessibility and promoting Ramayana Trail

$\mathrm{H} 4$ : There is a positive relationship between amenities and promoting Ramayana Trail

H5 : There is a positive relationship between ancillary services and promoting Ramayana Trail 


\section{Research Methodology}

The population is based on both demand and supply sides and was international tourists those who have arrived to Sri Lanka by year of 2016 January -August period has considered as demand side stakeholders where people involved operating in Ramayana sites has been considered for supply side (Community, tour guides, government, priest) in Central and Uva provinces. Sample size is 120 international tourists divided among two province based on Proportionate of Ramayana sites located in two province as table 1. For the supply side, four sites from Uva and two sites from Central province has considered with the 16 respondents as by taking two stake holders from each site.

Table 1: Sampling framework

\begin{tabular}{|l|l|l|}
\hline Province & $\begin{array}{l}\text { Sample } \\
\text { Size }\end{array}$ & Ramayana Sites \\
\hline Uva & 75 & $\begin{array}{l}\text { Rawana cave, Rawana fall, ,Diwurumpola } \\
\text { Rajamaha Viharya, Streeopura cave, Manawela } \\
\text { fall }\end{array}$ \\
\hline Central & 45 & Seethaamman temple, Laggala, Seetha fort \\
\hline Total & 120 & \\
\hline
\end{tabular}

\section{Results and Discussion}

Cronbach's Alpha Reliability Analysis has been proven the reliability as the overall alpha value is 0.772 is greater than the accepted level of 0.7 . All five variables has been tested for reliability test as the Scaled analysis (five point Likert Scale) used to rate.

\section{Graph 1- Distribution of region in Uva Province}

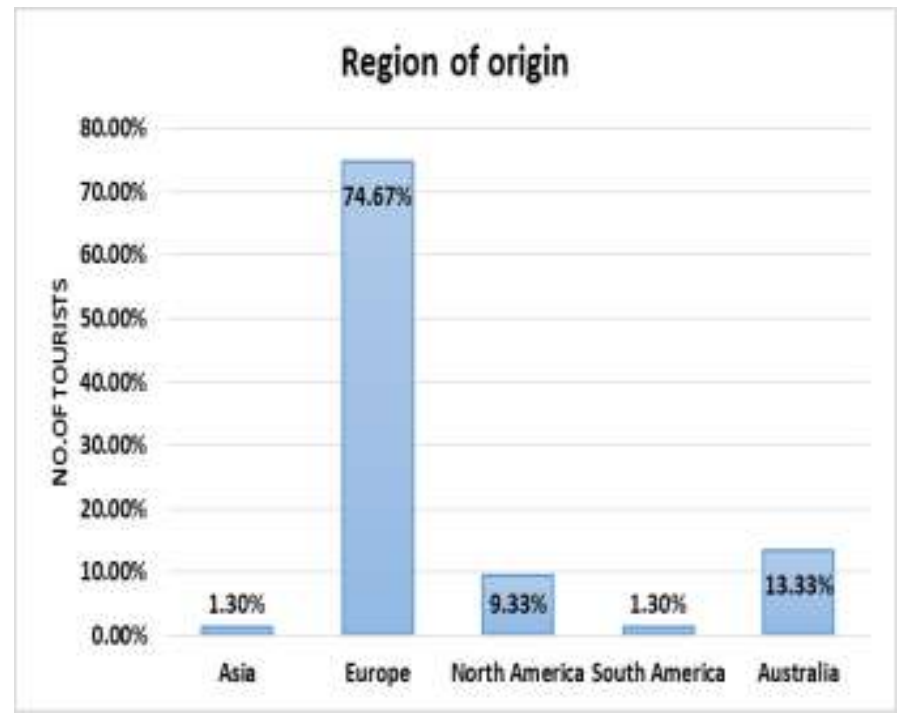


Among the sample of Uva Province, $74.67 \%$ of tourists were Europeans represented mainly the countries Netherland, UK, France and Germany,13.33\% Australians, 9.33\% from North and South America and Asia, about 1.3\% (Graph 1).

\section{Graph 2- Distribution of region in Central Province}

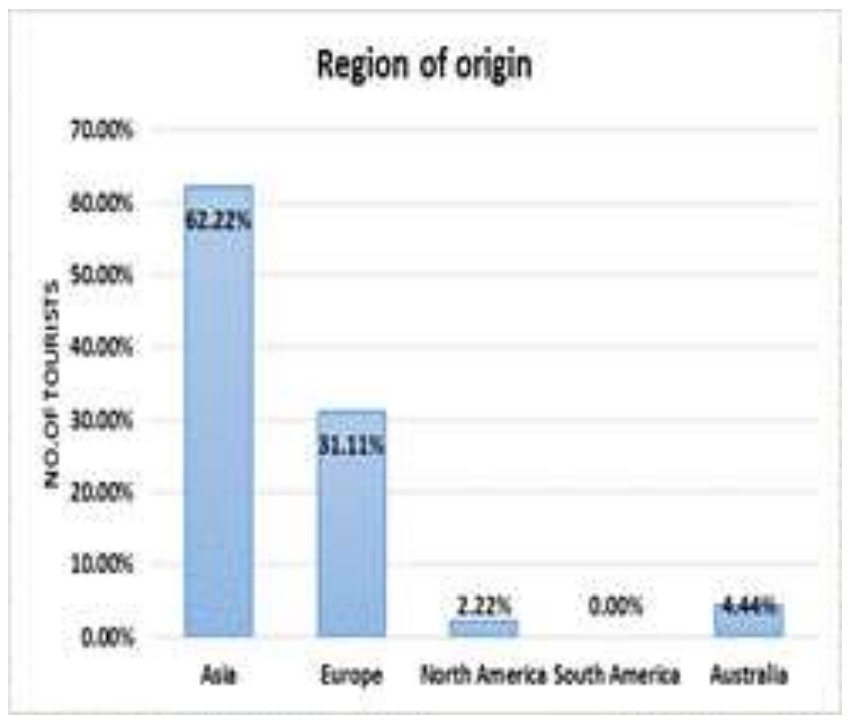

As a comparison, among the sample of Central province (Graph 2), 62.22\% of tourists were Asians and Indians, $31.11 \%$ Europeans, $4.44 \%$ from Australia and $2.22 \%$ from North America.

\section{Graph 3- Distribution of Purpose of visit}

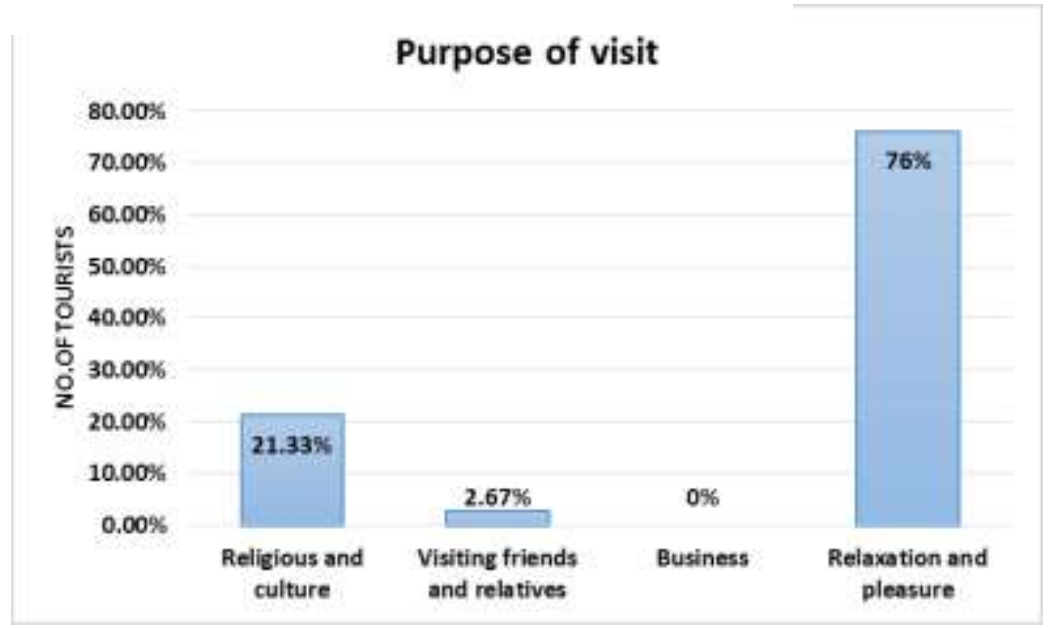

When considering about purpose of travelling (Graph 3), majority (76\%) of tourists were travel with the purpose of relaxation and pleasure , $21.33 \%$ religious and culture and $2.67 \%$ 
visiting friends and relatives. When concerning about travel companion, about $64.00 \%$ of tourists have travelled with friends and relatives while $21.33 \%$ of with spouse only. About $10.67 \%$ of respondents have traveled alone and $4.00 \%$ of tourists traveled with any other companions.

\section{Graph 4- Existing awareness Level}

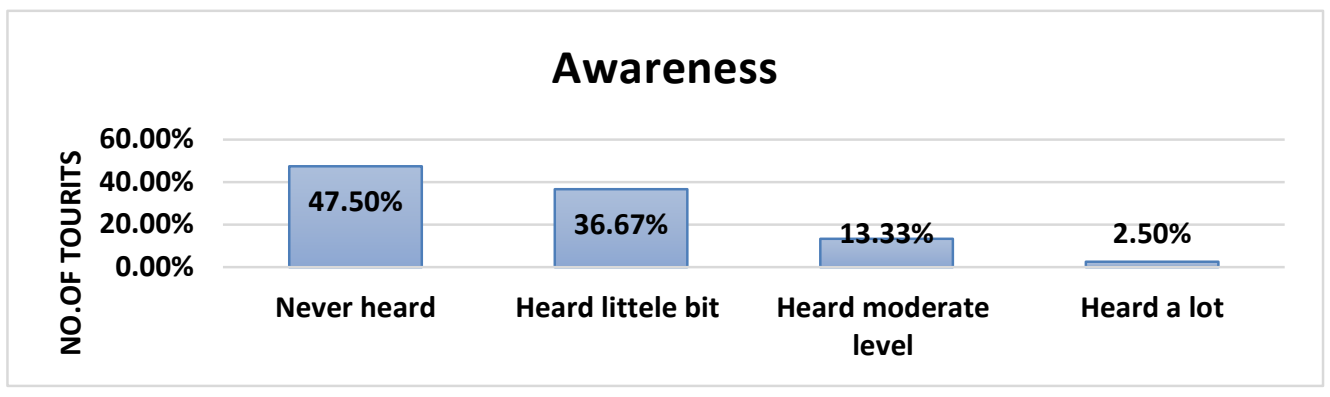

When considering about the Ramayana Trail awareness, Graph 4 demonstrates that, majority (47.5\%) of tourists were represented by the category of never heard and second highest awareness category (36.67\%) was heard little bit, $13.33 \%$ heard moderate level. Further the $66 \%$ of tourist have arrived to Ramayana sites without knowing Ramayana Trail and $34.17 \%$ by knowing the Trail. Further $80 \%$ were willing to aware about Ramayana Trail and $20.56 \%$ of tourists not willing.

\section{Graph 5- Problems faced during travel to Ramayana sites}

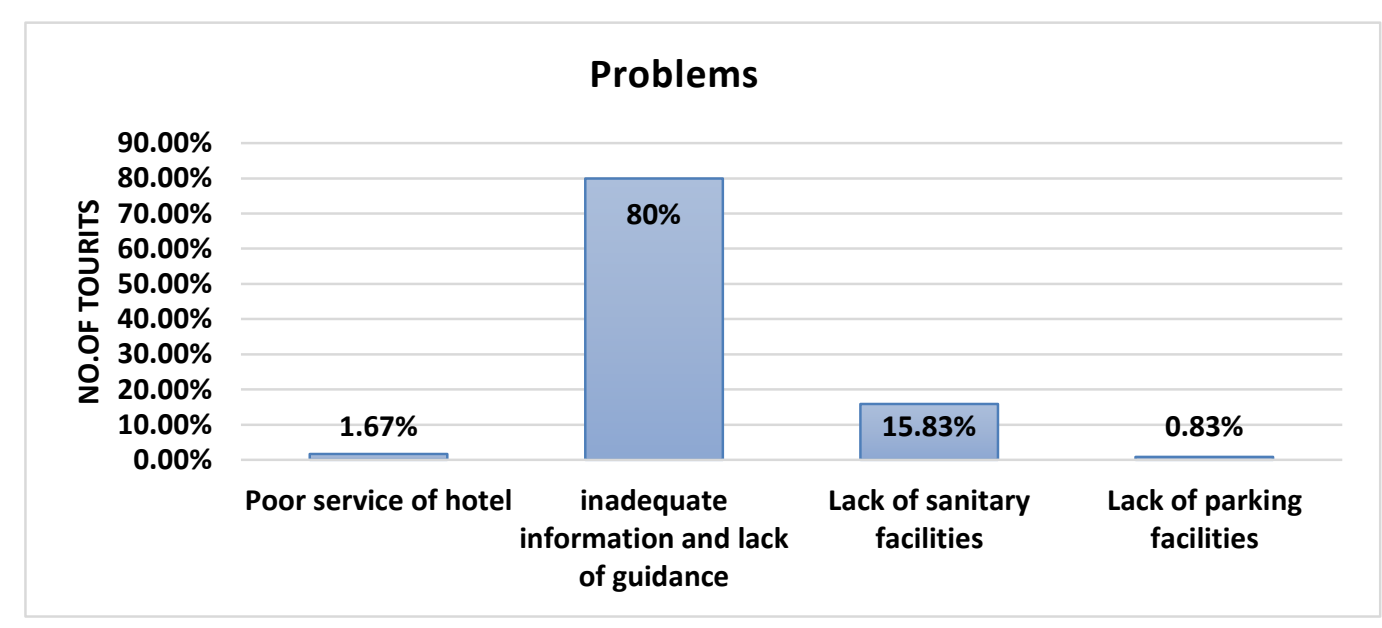

Out of total respondent (Graph 5), 80\% of tourists have identified inadequate information and lack of guidance as main problems faced during the travel,15.83\% lack of sanitary facilities and poor service of hotels $1.67 \%$. 
Table 2-Most influencing Destination Attributes to promote

\begin{tabular}{|l|l|l|l|}
\hline & Mean & Standard deviation & Variance \\
\hline Promotion & 4.1056 & .42939 & .184 \\
\hline $\begin{array}{l}\text { Avg. } \\
\text { awareness }\end{array}$ & 4.2583 & .61488 & .378 \\
\hline Attraction & 4.0778 & .54616 & .298 \\
\hline Accessibility & 4.0417 & .75539 & .571 \\
\hline $\begin{array}{l}\text { Ancillary } \\
\text { service }\end{array}$ & 4.2222 & .40615 & .165 \\
\hline Amenities & 4.1958 & .54732 & .300 \\
\hline
\end{tabular}

Source: SPSS output from field information

Awareness represent the highest mean value of 4.2583, and Ancillary service, Amenities, Attraction, Accessibility have considerable impact on promotion of Ramayana Trail ( 4.2222, 4.1958, 4.0778 and 4.0417 respectively). Multiple Regression Analysis indicates the predictive potential of destination attributes and promotion of Trail.

Table 3- Model summary of Multiple Regression Analysis

\begin{tabular}{|l|r|r|r|r|}
\hline Model & R & R Square & Adjusted R Square & $\begin{array}{c}\text { Std. Error of the } \\
\text { Estimate }\end{array}$ \\
\hline 1 & $.663^{\mathrm{a}}$ & .439 & .415 & .32848 \\
\hline
\end{tabular}

Source: SPSS output from field information

Results demonstrate destination attributes have explained $66.3 \%$ of the variance in the promotion of Ramayana Trail and explained variance of 0.663 is greater than 0.4 . The adjusted R-Square value (41.5\%) of this new model has no extensive difference, when compare to the previous result of R-Square value (43.9\%) and indicates regression equation is fitted. Standard error of estimation is 0.32848 represents that model is fitted well as mean value of dependent variable (4.1056) greater than standard error of estimation. 
Table 4 - Multiple Regression Analysis

\begin{tabular}{|l|l|l|l|l|}
\hline \multicolumn{1}{|c|}{ Predictor } & B Coefficients & Standard error & t-Value & P-Value \\
\hline (Constant) & .998 & .382 & 2.612 & .010 \\
\hline Avg_Awareness & .158 & .073 & 2.169 & .032 \\
\hline Attraction & .260 & .071 & 3.680 & .000 \\
\hline Accessibility & .127 & .048 & 2.650 & .009 \\
\hline Amenities & .120 & .060 & 2.009 & .047 \\
\hline Ancillary_service & .180 & .084 & 2.148 & .034 \\
\hline
\end{tabular}

Source: SPSS output from field information

Constant $\left(\beta_{0}\right)$ implied that while all five dimensions (Destination attributes) remain zero, Promotion of Ramayana Trail is 0.998 . The P-value of the constant is 0.010 and it denotes that statistically significant at 0.05 level of significance. The most significant factor is Attraction and awareness, accessibility, amenities, ancillary service also have positive relationship since table shows as positive values. In according to the above illustrated information, multiple linear regression model can be predicated as follows.

\section{$\mathrm{PRT}=0.998 \beta 0+0.158 \mathrm{AW}+0.260 \mathrm{AT}+0.127 \mathrm{AC}+0.120 \mathrm{AM}+0.180 \mathrm{AN}+\varepsilon$}

Where, PRT $=$ Promotion of Ramayana Trail

$\beta_{0}=$ Intercept Parameter, $\beta_{1}=$ Slope Parameter, AW =Awareness

AT $=$ Attraction, $\mathrm{AC}=$ Accessibility, $\mathrm{AM}=$ Amenities, $\mathrm{AN}=$ Ancillary Service,$\varepsilon$

$=$ Standard Error

The $\beta$ coefficient of awareness is 0.158 when Awareness was increased by one unit while other variables remain constant; the promotion of Ramayana Trail was increased by 0.158 units and significant since $\mathrm{P}$-value of 0.032 . Therefore null hypothesis $\mathrm{H}_{0}$ was rejected and the alternative Hypothesis $\mathrm{H}_{1}$ was accepted and there exists a significant relationship between awareness and promotion of Ramayana Trail. The coefficient of Attraction is 0.260 when one unit increment of attraction while other variables remain constant, and promotion of Ramayana Trail was increased by 0.260 and variable is significant and the alternative hypothesis $\mathrm{H}_{2}$ was accepted. Hence, there was a significant relationship between attraction 
and promotion of Ramayana Trail. In according to the illustrated result of accessibility, one unit of increase in accessibility while other variables remain constant, promotion of Ramayana Trail was increased by 0.127 and variable is significant and alternative hypothesis $\mathrm{H}_{2}$ was accepted. The coefficient of amenities is 0.120 when one unit increment of amenities while other variables remain constant, and promotion of Ramayana Trail was increased by 0.120. the alternative hypothesis $\mathrm{H}_{2}$ is accepted and a significant relationship between amenities and promotion of Ramayana Trail. For Ancillary services while other variables remain constant, promotion of Ramayana Trail was increased by 0.180 and variable is significant. The alternative hypothesis $\mathrm{H}_{2}$ is accepted and a significant relationship between ancillary service and promotion of Ramayana Trail.

\section{SWOT Analysis}

\section{Strengths \\ - Location \\ More than fifty places have identified as Ramayana sites fill with natural beauty, cultural and religious value, and manmade attraction. \\ Some places are located near to the famous tourist destination as Ella (Rawana waterfall/ cave), Nuwara Eliya (Seetha Amman temple)}

\section{- Infrastructure development}

Massive infrastructure development as high way projects, road development, railway development.

\section{- Historical value}

Ramayana Trail has a great prehistorically value

\section{Weaknesses}

- Awareness

Awareness of foreign tourists regarding Ramayana Trail is less.

\section{- Lack of promotion}

limited number of websites and Government involvement to promote

Ramayana sites and this legend

\section{- Lack of information and guidance}

Limited number of information sources available and no proper information on sites, direction, available routes and activities.

\section{- Implementation}

The attention of responsible authorities is comparatively low as no any official plan was implemented yet. 


\begin{tabular}{|l|l|l|}
\hline Opportunities & Threats \\
- Increasing tendency towards cultural & - Cultural deterioration \\
tourism; cultural and historical values & - Environmental issues may caused \\
in destination. & - Ramayana legend has lack of \\
- Ramayana Trail can be better & evidences to prove \\
promoted to Indian tourists as the & \\
cultural product \\
$\begin{array}{l}\text { Local community can involve with } \\
\text { Ramayana Trail activities as such }\end{array}$ \\
local tour guide service. \\
opportunity to promote Sri Lankan \\
prehistorically value
\end{tabular}

\section{Conclusion and Recommendation}

The objective of the study to identify promote Ramayana Trail as a cultural tourism product and the visitor profile, existing level of awareness regarding Ramayana Trail, opportunities and barriers to promote Ramayana Trail and most significant destination attributes has been taken in to consideration. When considering the exiting level of awareness most of tourists (48\%) never heard about this legend and reveals still the awareness level considerably less. Although most of European tourists did not aware of the legend, expressed their awareness of Rama and Seetha story and $36.67 \%$ of tourists have heard. More than half of Indian tourists already aware about Ramayana which was a part of their religion but not aware about Ramayana sites and their specialty. Rawana waterfall and Rawana cave have already promoted among many tourists since those were located around Ella area but no awareness given on Ramayana legend. About $80 \%$ of tourists were willing to know regarding Ramayana Trail and most of European, Australian and American tourists show their interest. Tourists expect more information service and promotional material to know about Ramayana sites, activities, routes as well infrastructure and superstructure. Tourists have agreed with existing situation of destination attributes and among the five dimensions of destination attributes, Awareness represent the highest mean value of 4.258 and indicates tourists have agreed with awareness as most essential factor to promote Ramayana. Furthermore, ancillary service, amenities, attraction and accessibility also have significant influence on promotion of Ramayana Trail represents the mean value 4.22, 4.19, 4.08, 4.042 respectively. Five 
dimensions had significant impact on promotion as Attraction had highest impact on promotion and availability of peaceful atmosphere of the destination, manmade attraction, and beautiful scenes of the destination had highest impacts. Accessibility was the second highest influencing factor and parking facilities, proper transportation, and adequate terminals were highlighted. Tourists had considered on accessibility for the particular destination. Awareness was the third and ancillary service is the fourth highest destination attribute. Tourists were considered availability of telecommunication, availability of sanitary facilities and availability of safety and security had impact on promotion of Ramayana Trail. Amenities had the least impact on promotion than other four variables and availability of food/beverages and accommodation facilities of sites were consider lower than the other factors when promoting the trail. Ramayana Trail is a sophisticated niche market for Sri Lankan tourism industry and novelty nature would be plus point to promote among tourists. When considering about the percentage of tourists arrival to Sri Lanka, Indian tourists' percentage is high (SLTDA statistics) and Indians already aware of the legend and could be promote. Although Indians are aware about the trail they are not aware on the Ramayana sites due to lack of promotion and information service. Involvement of local tour guides is need even though some guides are not willing to promote this due to lack of evidence. Accordingly Ramayana Trail need more promotion through internet sources; website, blogs, and social media.

Following Recommendations could be made;

\section{Promotional plan through an official authority due to the trustworthy}

- Massive promotional activities can be implemented to increase awareness level of tourists : Internet sources/web blogs, social media marketing, E-word of mouth and printed media

- Information (information Centre /hoardings/boards/directions to other nearest sites) near to the Rawana waterfall : printed material; leaflets, books, magazines tourists can be informed on Ramayana sites

- Tourists can be directed to sites by prioritizing their prehistoric value, routes, activities

\section{Proper information base regarding Ramayana trail tour}

- Official helping hand to promote Ramayana Trail tour by registered travel agencies

- Pro-active and well-targeted marketing activities : Ramayana trail mapping in international travel agencies/booking agencies 
- Assistance of Archeologists to create accurate information base for Ramayana Trail and sites

\section{Promote Ramayana Trail combining with other prominent niche tourism markets}

- Rawana cave to promote with cave tourism

- Religious tourism to promote Seetha Amman temple

- Eco and Adventure tourism combine with Ramayana Trail

\section{Proper mechanism to sustain facilities with the participation of local community}

- Introduce an entrance fee for the cultural sites and basic sanitation

- establish accommodation and food catering facilities for tourists

\section{References}

Buhalis, D. (2000). Marketing the competitive destination of the future. Tourism management, 21(1), 97-116.

Fernando, I. N. (2015). What Competitive Strategies Way forward the Regional Competitiveness? A Comparative Economic Approach to Sri Lankan Tourism. International Journal of Business and Management, 10(4), 178.

Fernando I.N.,'Tourism Competitiveness: A Cluster based approach for the Sri Lanka", International Conference on Contemporary Management (ICCM-2014), University of Jaffna, 14-15 March, 2014

Foad Z.Y., Fazel H.E. and Amin M.,(2014), Promoting Tourism destination: Heritage, History and Culture in International Tourism, International Journal of Information Technology and Management Studies- 1(1), 1-32

Hall, C. M., \& Lew, A. A. (2009). Understanding and managing tourism impacts: An integrated approach. Routledge.

Hofstede, G. (2011). Dimensionalizing cultures: The Hofstede model in context. Online readings in psychology and culture, 2(1), 8.

Hudson S. \& Ritchie J.R.B, 2006, Promoting destination via film tourism: An empirical identification of supporting marketing initiatives, Journal of Travel Research http://www.ramayana.lk/index.html 
Jayasinghe D., 2013, Historicity of Rawana and Trails of Rama-Seetha in Sri Lanka - The Ramayana in literature, society and the Arts, The C.P. Ramaswami Aiyar foundation McKercher, B., \& Du Cros, H. (2002). Cultural tourism: The partnership between tourism and cultural heritage management. Routledge.

Prentice, R. (2001). Experiential cultural tourism: Museums \& the marketing of the new romanticism of evoked authenticity. Museum Management and Curatorship, 19(1), 5-26.

Munsters, W. (2010). 5 The Cultural Destination Experience Audit Applied to the Tourist-historic City. Cultural Tourism Research Methods, 52.

Silberberg, T. (1995), Cultural tourism and business opportunities for Museums and Heritage sites. Tourism Management, 16(5), 361-365.

SLTDA 2014, Sri Lanaka Tourism Development Authority Statistics Report

Sofield H.B \& Li F.S, (1998), Tourism development and cultural policeis in China, Annals of Tourism Research, 25(2),362-392

Tighe, A. J. (1986). The Arts/Tourism partnership. Journal of Travel Research, 24(3), 2-5.

Bose, M. (Ed.). (2004). The Ramayana Revisited. Oxford University Press.

Balambal V, (2013), Ethical Value of Ramayana ;The Ramayana in literature, society and the Arts, The C.P. Ramaswami Aiyar foundation 